\title{
MEMORIA Y OLVIDO, UN LIBRO DE PABLO D`ORS
}

\author{
Maria Luisa Santos Gómez \\ Licenciada en Filosofía - Universidad de Sevilla \\ "Olvido de lo criado; \\ memoria del Criador; \\ atención a lo interior; \\ y estarse amando al Amado". \\ (Juan de la Cruz, \\ Suma de la perfección)
}

En El olvido de sí. Una aventura cristiana obra de Pablo d'Ors (Pre-Textos, 2013), confluyen diversos mundos unificados por un proceso vital de búsqueda de sí mismo. Su título es sugerente e inquietante. Trata de mostrar la aventurera vida de Carlos de Foucauld incansable buscador de sí mismo, enamorado entusiasta e imitador de Cristo, mártir silencioso y olvidado. En consecuencia, el mundo central que nos presenta este insólito texto es el de la religión, pues, como aclara el subtítulo, se trata de "una aventura cristiana". Una de las enseñanzas más profundas que nos aporta es la que suscita el fracaso asumido.

El texto se configura conforme al género autobiográfico muy familiar al autor. Pero, al ser su protagonista un personaje real y presentarse novelado, su referencia es doble. Estamos ante dos modos de narración, histórica y novelesca, con sus correspondientes 
modos de verdad entrecruzados. $\mathrm{El}$ autor ha tenido que sortear la dificultad de aunar y concordar la realidad y la irrealidad, la verdad histórica, exigida por la realidad del personaje, y la verdad de la ficción que también requiere toda creación literaria. Nos encontramos ante una vida novelesca que parece real. Y lo es. Y una realidad que parece irreal por las situaciones, avatares, paisajes, cambios y transformaciones del protagonista...que también lo es. Es difícil marcar la línea que separa la realidad y la irrealidad, pues la historia que fue se eleva por gracia de la palabra a un nivel ideal donde se expresa lo mejor de la vida del narrador. Y quizá de la del autor.

En consecuencia, no puede extrañarnos que a veces la verdad literal ceda ante la verdad de la creación poética pues ésta capta el sentido del acontecimiento narrado mucho mejor que la mera literalidad. Por ejemplo, en su segunda conversión, verdadero "nacimiento espiritual", la leche de cabra que le salva la vida se pone en unas manos negras infantiles, las de Ouksem, cuando en la realidad fueron los tuareg, sin determinar la edad, quienes lo ayudaron. Pero, de este modo, se realza más la pobreza del ermitaño que recibe la salud -la salvación- de un ser tan desvalido como un niño. Y así puede ocurrir con otros episodios, el alterar el lugar, el momento y las circunstancias se justifica para subrayar precisamente su sentido.

La referencia, lo narrado, en este texto excepcional, nos arrastra con una dinámica envolvente acorde con la vida del protagonista. Y nos conduce de la admiración al desconcierto, de la exclamación al silencio, del movimiento inquietante a la quietud más perpleja, desde la riqueza de un origen aristocrático hasta la extrema pobreza. Todo es contraste, cambio continuo, transformaciones sorprendentes, pero también es serenidad, permanencia, silencio. En verdad, parece increíble esa historia llena de acontecimientos insólitos, de situaciones límites, de la abrumadora concordancia de fuerza y debilidad, voluntad y abandono. Pero, a pesar de lo anterior, la construcción de la obra nos da espacio y dosifica sus pausas. De este modo, se abre una relativa distancia en la que podemos gozar de los aspectos lingüísticos y literarios del texto: su sintaxis, el léxico, el ritmo...su música singular. También, de la estructura, de la secuencia de los parágrafos, de los contrastes, en suma, del excelente modo de decir y configurar 
El autor nos va llevando desde la confusión inicial del protagonista hasta la cima de su iluminación, pasando por la conversión, la imitación de Cristo, la purgación y la compasión. Ocho etapas, en creciente profundización, ahondando en el descubrimiento de sí por el olvido de sus pertenencias: del tener al ser. Y, sin apenas darnos cuenta, vamos siendo transportados a esos variados paisajes donde se enlaza la búsqueda de la identidad, la llamada de la vocación, el tiempo perdido y recobrado (redimido) a través de la memoria, la escritura y el perdón; la diferencia y unidad de las impresiones sensibles y el logos. Pasamos de los personajes y escenarios mas familiares (el abuelo, los compañeros y amigos, su prima y el abate), a los más extraños: los pobres y abandonados; de las grandes ciudades, Paris, Roma, Casablanca, a los desiertos del alma y sus inefables horizontes, para culminar en el lugar de su martirio. Pero, en medio de este trasiego de acontecimientos y transformaciones, nuestro proteico protagonista va conquistando su mejor espejo: la vida oculta de Cristo.

Todos los elementos anteriormente indicados sirven para configurar una historia en la que se armonizan la realidad y la ficción, la vida del protagonista y la del mismo autor que se expresa como si fuera el mismísimo Foucauld. Dificilmente se puede encontrar una identificación mayor entre ambos de tal modo que el uso de la primera persona da a la ficción una fuerza que, en muchos momentos, resulta indiscernible de la realidad. Son escasos los instantes en los que el autor abre una fisura por donde cuela sus proyecciones. Pero la acción, la estructura, los personajes, las etapas del recorrido, se orquestan en toda la obra con una admirable sabiduría. Y todo está cuidado con tal esmero y pulcritud que da la impresión de la gozosa espontaneidad que solo una obra maestra puede suscitar.

\section{PROTEO O EL PLACER DE TRANSFORMARSE. LA IDENTIDAD BUSCADA}

Como Proteo, símbolo mítico del devenir humano, el protagonista de esta historia se transforma a través del tiempo. Y va construyendo su identidad al hilo de sus múltiples cambios que son, paradójicamente, un camino de desapego. El gusto por travestirse se hace más profundo y radical cuando afecta no solo a los vestidos, 
sino a las formas de vida del vizconde. Muchas transformaciones le constituyen y configuran. El juego de los disfraces le persigue casi hasta el final de su vida y su conciencia desdoblada le lleva a preguntarse sobre la autenticidad de ellos. Nadie sabe quien es hasta que se ha desplegado su vida. Así, se pregunta literalmente en dos ocasiones si no estará usando un disfraz para "camuflarse". Cuando lleno de harapos recorría las calles de Nazaret (\&50), le "asaltó una idea dolorosa y clarificadora" de que su situación vital fuera un "nuevo disfraz del viejo e incorregible vizconde de Foucauld" (...) Una nueva impostura...Aun después de convertido no había dejado de ser quien siempre había sido ¡Un bufón!, (p. 198). Estas expresiones tal vez resulten demasiados fuertes para un converso sometido a la disciplina de los ayunos y pobreza. Y ese desdoblamiento un poco excesivo para una persona con vocación definida y confianza en su Señor ¿Es el autor el que, en cierto modo, proyecta su propio desdoblamiento sobre el protagonista?

La segunda situación a la que nos referíamos es cuando se identifica con el lexicógrafo y acepta su legado: repite casi literalmente las mismas palabras que cuestionan su nueva identidad con un desdoblamiento similar. Cierto que esas múltiples transformaciones pueden parecer, como en Montaigne, un ensayo consigo mismo para conocer quien es, un medio de autoexploración. "Me he pintado a mi mismo", decía el autor de los Ensayos manifestando que la materia de su libro era su propio yo. Pero esta autobiografia tiene un sentido distinto. El autoconocimiento esta orientado por el gusto en el propio análisis $\mathrm{y}$, a veces, por provocar el reconocimiento ajeno, no para descubrir los caminos que Dios quiere para el yo.

Peregrino, monje, recadero, ermitaño, sacerdote...hasta llegar a ser el hermano universal. Ninguna figura satisface al inquieto buscador, ningún disfraz permanece: sus transformaciones no cesan. Pero no estamos en esa manía de la modernidad que exalta la autoconciencia como forma de poder, sino ante un medio para conocer la voluntad de Dios. Este cambio del sentido de las transformaciones hay que retenerlo. Así, tuvo que "inventar muchas identidades" hasta encontrar la que Dios queria para él. De este modo, dando espacio a esas múltiples figuras, dejaba que se manifestaran todos los rostros que Dios le iba mostrado. Pues sitúa el origen de su vocación en el mismo instante de su conversión. 
¿Quién dice "yo" en esta fascinante historia? ¿Qué permanece en los cambios, a veces de un ritmo vertiginoso, dando unidad y continuidad a este personaje? ¿Quién es el que subsiste trasciende- en las múltiples formas de su transcurso vital y cuál sería su auténtico rostro? ¿Qué queda de este joven amante de los placeres, mujeriego, provocador, exaltado, en ese anciano cuyo rostro se muestra paciente dulce e iluminado? Nos preguntamos quién es el que dice de sí mismo que su voracidad era insaciable y que había llegado al final de su vida a ser quien era: una persona desprendida de todo egoísmo y dispuesta al martirio. Es decir, la pregunta se dirige a la identidad que constituye el núcleo de su ser.

Otro grupo de cuestiones gira en torno al destinatario de su historia, al motivo y finalidad de esas memorias cuyo cuadernillo se encontró entre las pobres y escasas pertenencias del mártir. Y, por último, deseamos aclarar desde dónde se narra, cuál es el horizonte de luz en el que se van a situar todos esos acontecimientos $\mathrm{y}$ transformaciones del protagonista. Son, en verdad, muchas preguntas las que esta vida suscita en cualquier lector. Porque lo que se es no es lo mismo que quien se es.

La dialéctica entre quién se es y lo que se es permanece a través de todas las configuraciones hasta disolverse, casi, al final. Desnudo de sí mismo, desposeído de todo, el anciano contemplativo es ya casi un puro quién sin sostenerse en lo que es porque se ha desprendido de todos sus modos de tener, vaciado y anonadado incluso de lo que constituía su carácter.

Y. no obstante, se puede reconocer al protagonista, a pesar del increíble cambio de su rostro al ritmo de su transformación interior, del viaje hacia su propia interioridad. Se mantiene el ser sí mismo inquieto y buscador. En toda búsqueda late lo buscado. Foucauld fue una persona exploradora y apasionada. Y extranjero, como si no fuera de este mundo. Pero siempre hubo en su vida un espacio, al principio minúsculo, para la generosidad. La llamada del desapego le orientaba en su deseo de Dios. Por eso, la memoria de su vida unifica los momentos de su temporalidad: pasado, presente y futuro anticipado. De este modo su ser proteico muestra otro rasgo de la divinidad griega: el conocer del tiempo. Pues la sabiduría de las tres dimensiones temporales profetiza su futuro, 
anticipando su martirio. Porque solo desde la memoria se puede recobrar el tiempo perdido que resulta así unificado. Solo desde la escritura se puede intentar vencer la disolución. Pero solo desde la imitación a Cristo se puede vivir desde la salvación. De este modo, a pesar de la insatisfacción permanente que le impele a cambiar, a pesar de la pobreza, el ermitaño tiene la certeza interior de ir siempre misteriosamente orientado.

Por eso su escritura es la historia, como veremos, no solo de su vida sino de la de Dios en él, al quedar configurada por su mejor modelo, la imitación de Jesús. Permanece lo buscado y encontrado en su conversión. No hay identidad más firme que la constituida por una vocación. Ni mas profunda que la configurada por la vocación religiosa. El converso mantiene la búsqueda de su mismidad que va logrando con el olvido de sí: estupenda paradoja. Y así llega a la dicha de la identidad lograda en la consumación de su vocación, la iluminación esperanzando el martirio. En este sentido, anticipamos que su escritura no sería el reflejo del último latido del narcisismo, como un lector malicioso podría suponer, sino el ultimo gesto de la entrega de sí, del amor del apóstol a su Señor.

El tema de la identidad es muy querido por el autor y recurrente en todas sus obras. En Las andanzas del impresor Zollinger, el protagonista pasa también por diferentes oficios y a todos se dedica con amor, a todos los cuida con esmero hasta llegar a su destino definitivo. Recordemos "el brillo Zollinger" de los zapatos que lustraba. Pero, en este caso, la sencillez y bondad del personaje, el modo natural y sereno en que fluian sus oficios no alteraba su identidad. El vizconde, en cambio, es apasionado y, en cierto modo, amante de la desmesura e impulsivo en todo lo que emprendía, proclive al exceso. "Siempre he predicado la moderación y siempre he sido un exagerado", (p. 166). Se entregaba a sus disfraces deliberada y voluntariamente, diríamos con apego, mientras duraban. Ese afán y vivencia del tiempo, ese trasiego del pasado al futuro y ese vértigo del cambio -no estar plenamente donde estaba, ser un extrañoestá ausente en el impresor. Éste vive el presente en serena quietud, instalado casi en la realidad sin añoranzas, ni ansiedades. Es lo que es en cada momento: presencia de la contemplación. El cambio de los oficios y lugares por los que pasa no rompen la armonía interior de este hombre paciente y silencioso. Y esto Foucauld solo 
lo conseguirá poco antes de morir. "Soy sedentario por naturaleza, pero nómada por vocación", (p. 340).

Parecido talante tiene Alois, el sereno narrador y protagonista de El estupor y la maravilla. Ama su oficio de vigilante de museo hasta tal punto que su uniforme forma tal unidad con su propio cuerpo que su mejor modo de dormir es con él puesto. También el vigilante pasa por distintas salas del museo en el que trabaja, por diversos mundos que dejan su huella en su identidad. Pero todo transcurre de forma sosegada, sin ritmos trepidantes, en el ámbito que abre la contemplación. Del mismo modo, el joven y curioso protagonista de Lecciones de ilusión pasa por diversos rostros de la locura para poder constituirse como él mismo cuando sale del hospital de san Bonifaz abierto a su nueva vocación. En todos estos casos, se trata de mostrar que la constitución de la identidad pasa por el rodeo de la alteridad. Y, por último, recordamos al atormentado profesor de filosofia, de Las ideas puras. También busca su identidad, pero de forma obsesiva y perturbada, a través de las oscilaciones de un imperioso deseo de poseer y gozar sin lograr, en su turbulenta aventura, nada más que... llegar al punto de partida. El tiempo se detiene en la tediosa repetición de lo mismo sin alcanzar un momento de paz, sino la permanencia en el infierno de la frustración. Contrafigura, sin duda, del vizconde en múltiples aspectos que sería inadecuado detallar aquí. A pesar del deseo de infinitud, de absoluto, que latía en ambos, el transcurso de sus vidas y sus horizontes los distanciaba abismalmente. En fin, podiamos concluir que la búsqueda de la identidad va del deseo al vacío interior y a la recepción de la gracia, pasando por Proteo. Así, puede marcarse la trayectoria no solo de la novela que comentamos sino de la narrativa de su autor. Hasta ahora.

\section{DAR Y RECIBIR, “EL VERDADERO NACIMIENTO ESPIRITUAL”. UN VASO BLANCO EN UNAS MANOS NEGRAS}

El camino del abandono encuentra un punto decisivo, incluso después de años de conversión, cuando el peregrino aprendió a recibir. Antes tuvo que vaciarse de sus propiedades, no solo externas, sino las constitutivas de su propia personalidad. Sin ideas, sin control de su voluntad, sin sentimientos, su extrema 
pobreza llegó al límite de tener que ser ayudado por los pobres. Enfermo, solo y abandonado en aquellos parajes desiertos e inhóspitos, se sentía morir. "Ven sin nada" le oía decir a su Señor. $\mathrm{Y}$ es que ya solo le quedaba el dolor y el llanto. Pero, de pronto, la luz: unas manos negras infantiles le ofrecían un vaso de leche de cabra. Ouksem, el cabecilla de la pandilla que tanto le había torturado, se presentaba como un ángel custodio. Dejarse ayudar y aprender a recibir fue una lección que le costó "la vida entera". En esta situación límite vivió la experiencia de la pobreza en toda su profundidad. Esas manos ofreciendo ayuda marcan el momento de su nacimiento espiritual. El episodio culmina con una reflexión: el dar nos asemeja a Dios, pero el recibir lo supera porque en la pobreza reconocemos mejor su Rostro.

\section{ORACIÓN Y AMOR AL PRÓJIMO. EL DON DE SU UNIDAD. EVANGELIZAR DESDE LA AMISTAD}

"Tanto más amaba a mis semejantes cuanto más rezaba por ellos. Hoy puedo afirmar que mi manera de querer es, fundamentalmente, orando o, lo que ese lo mismo, que orar es para mí el mejor sinónimo de amar. Todavía más: no concibo un amor que no derive en oración", (p. 308).

El texto anterior expresa de modo rotundo y claro la profunda unidad entre amor a Dios y al prójimo que hay en el creyente. Podiamos decir que la vocación social encuentra su culminación en el horizonte de la vocación religiosa. "Poner ante Dios" a los que se ama es, para el protagonista en la etapa de compasión, "lo mejor que puede hacerse". Y no solo por quienes amamos sino por quienes deberíamos amar más. La oración debe preceder a toda acción importante y agradecerla después, como ocurre con la página que el narrador acaba de escribir. Solo por un momento tuvo la tentación de olvidar a Dios por cuidar a sus criaturas, pero lo superó.

Si tuviera que seleccionar un parágrafo de todos me quedaría con el \& 91, Todos los nombres, anticipado por el que comentamos, \&84, El poder de la intercesión. Ambos expresan la perfecta armonía entre el amor a Dios y al prójimo. De este modo, la oración 
da sentido último a la vida. Y, hasta tal punto, que el principio de identidad más certero, el criterio para discernir el valor de alguien, el "termómetro", se sitúa en "la calidad de su oración". Ser creyente equivale a "descubrir" que todo tiene sentido, que nada es azaroso, que todo va a conservarse. Así se expresa claramente la vivencia de un tiempo no meramente recobrado, sino redimido. "Cuanto más he mirado mi vida -lo que es tanto como decir cuanto más he orado- mas evidente me ha resultado que nada ha sido realmente insignificante. Creo que ser creyente significa descubrir que nada es casual y que nada va a perderse", (p. 337). Estamos en el polo opuesto al sentir de Marcel, el protagonista de la novela de Proust. Agobiado por el peso de la vejez y de la enfermedad, en la soledad de tener que terminar su obra, amenazada además por la posibilidad de morir antes, se angustia en el desconsuelo: todo puede perderse.

Y, no obstante, ante estos textos nos preguntamos por el sentido de las siguientes afirmaciones, "mejor dar limosna que ayunar y orar". En dos contexto se reitera la idea (\&75 y \& 86). "La limosna es un valor superior al ayuno y a la oración, puesto que solo se llega a comprender y a practicarla después de haber orado y ayunado mucho. Es más fácil orar que ayunar, y es más fácil ayunar que dar limosna”, (p. 279). No se ve muy concluyente. Precisamente porque recibe su sentido de algo superior la limosna queda contenida en un horizonte más amplio; sería inferior puesto que solo se comprendería desde lo más alto: haber orado mucho. Tampoco está claro el criterio de la facilidad, pues no vemos porqué la dificultad tendría superioridad jerárquica. Además, parece no concordar con los parágrafos 84 y 91 en los que el sentido religioso prevalece sobre el estético y social. "La hospitalidad es un paso superior a la limosna, así como la limosna es un paso superior al ayuno y a la oración, (p. 313). ¿Se impone en estas opiniones el hombre social para quien el valor máximo es el prójimo?

En cualquier caso, al dejar el "celo evangelizador", es decir, la obsesión por evangelizar, lo hacía mejor. "En realidad, se hable o no de Dios, siempre se evangeliza si se lleva a Cristo dentro. A decir verdad, nunca he querido predicar con la palabra sino con las obras", (p. 311). Sin embargo... se elogian las palabras cuando se trata de recogerlas para salvarlas del olvido en el diccionario 
tuareg, y se desea que vivan "la vida de los libros". ¿La palabra de Dios no puede ser dicha con el mismo esmero y humildad que las poéticas que se quiere inmortalizar con la escritura? Parece que el escritor sustituye, con estas valoraciones, al santo, situando la vocación estética más alta que la religiosa. Resulta dificil ejercer los tres pilares de la evangelización -hacer el bien, enseñar y ser hospitalario-, si la palabra no acompaña a la acción. El mismo narrador se adelanta al lector expresando que una de las contradicciones de su vida es tener que evangelizar y "al mismo tiempo" sentir el impulso a la contemplación. "Una de las grandes contradicciones de mi vida ha sido la necesidad de evangelizar y, al mismo tiempo, en el mismo movimiento, la de callar y limitarme a la contemplación (...) Resulta extraño que hable tanto de la evangelización sin palabras cuando a lo largo de mi vida son millones las palabras que he llegado a escribir en particular sobre la Biblia”, (p. 325). De cualquier forma, el misionero no puede evangelizar desde una actitud de maestro, sino de "discípulo y amigo del pueblo", aprendiendo de los pobres que, como los enfermos y desvalidos, nos evangelizan. Y, añade que debe hacerse "desde la debilidad, nunca desde la fuerza". Asimilar esta lección le "costó sudor y sangre".

Surgen algunas dudas relativas a las connotaciones peyorativas que tiene el término "fuerza" en el texto citado y también, respecto a la exaltación de la amistad como mejor medio de evangelizar. Fuerza es impulso, potencia, energía, proceda de la naturaleza o de la gracia. No necesariamente es orgullo, violencia, imposición, asociaciones que evoca el término en el contexto usado. En cuanto a la amistad, ¿no exige reciprocidad, semejanza, cercanía? Ver en el amigo también un hijo de Dios enaltece el amor. Y no digamos en el enemigo, como se indica con belleza y lirismo en "el poder de la intercesión". Contemplar al prójimo desde esa perspectiva, como hijo de Dios, valdría incluso aplicado a sí mismo como expresa Bernanos al final de su profunda obra, Diario de un cura rural: "Odiarse es más fácil de lo que se cree. La gracia es olvidarse. Pero si todo orgullo muriera en nosotros, la gracia de las gracias sería apenas amarse humildemente a sí mismo, como a cualquiera de los miembros dolientes de Jesucristo". 


\section{MIRADA, TACTO, PALABRA. LA EXALTACIÓN DEL CUERPO Y EL PODER DE LA PALABRA. LA DICHA DE LA INMEDIATEZ}

Sumamente cuidada, admirable, es la secuencia que nos lleva de las visiones al tacto pasando por la hospitalidad, la escucha y las postraciones ante el prójimo. Y, en el centro de todo, la oración: la exposición del santísimo y la intercesión por los necesitados. Es el camino que va hacia la inmediatez, pues en el tacto se realiza "el milagro de la comprensión"-Así, la imposición de las manos, "el tocar y el dejarse tocar" cierra y culmina este camino del reconocimiento que es solidariamente el de la exposición de sí mismo. Pero falta aún llegar a la palabra y a la escritura para que por ellas y en ellas se exprese y encuentre permanencia todo lo vivido en la comunidad de tuareg. No deja de sorprendernos gratamente, después de ese recorrido en el que cada sentido encuentra su plena expresión, la exaltación del logos. Porque, como veremos, no es la fama lo que impulsa a continuar la labor del lexicógrafo, sino la belleza y el deseo de permanencia.

La oración de intercesión y la escucha están unidas por un mismo impulso. Un camino de ida y vuelta va del "oratorio al locutorio". Doble era la escucha a su Señor, en la capilla y "en las quejas del desdichado". Pero, reconociendo el valor de servicio social, escuchar a los demás es prioritariamente una forma de evangelizar. De nuevo se armonizan la vocación social y la religiosa. En varios momentos el ermitaño confiesa que su medio de predicación no es "la palabra sino las obras". "Escuchar sin más, sin aconsejar ni amonestar, sin orientar, sin llegar a conclusión alguna, solo escuchar es lo que Dios hace preferentemente con los hombres", (p. 312). ¿Excesivo, quizá una nueva proyección? Pues cualquier lector puede evocar pasajes evangélicos en los que Jesús empieza escuchando, pero después continúa predicando y aconsejando. "Vete y no peques más", dice a la adúltera. "Que necios y torpes sois", a los discipulos de Emaús... pasaje ejemplar entre todos como modelo de evangelización.

La misma unidad entre el amor a Dios y al prójimo se destaca en las "postraciones" pues en él ve al mismo Cristo. Nos sorprende postrándose ante cualquier persona: beduino, comerciante, soldado, niños, mujeres y hombres, pobres y ricos. Pero sobre todo, ante los enfermos, acababa "rostro en tierra". De este modo, se 
condensa y simboliza la cima del "abajamiento". Había llegado a ser "amigo y servidor" de los pobres. Junto a ellos aprendió que amar es un ejercicio de atención. Consiste en olvidarse de sí y atender a lo que le "desubica".

El punto de llegada de este camino a la inmediatez es el tacto. Cuando lo descubrió, maravillado de su poder, no paraba de tocarlo todo. De este modo se transformó en "curandero", su nueva identidad. La intercesión se une al tacto, el pensamiento a la acción... Estamos muy lejos de la estéril pureza de las ideas que aprisionaban la mente del protagonista de Las ideas puras así como de su profanación del tacto.

Unos instantes de comunión surgen más allá de la mirada y de las palabras, pues sus manos "decían" lo que no llegaban a decir aquellas. Por unos momentos, en la imposición de las manos, sucedía "algo así como el Reino de Dios en la tierra". En el tacto se pone en juego la intimidad y la aceptación más insondable de las personas. Por ello, tocar a los pobres es aceptarlos de forma radical, pues ellos activan nuestra radical identidad. Así, se realizó otro cambio en su interior: se liberó del deseo de perfección mostrándose más atento a los demás.

El logos viene a culminar este proceso. La belleza de las palabras en la elaboración del diccionario francés-tamacheq, le envuelven, le arrastran hasta obsesionarle. La seducción del poder de la escritura y el deseo de salvar la belleza del olvido, ¿será una nueva tentación? Tal vez por unos momentos. O quizá nos encontremos con la proyección del autor en el personaje. En cualquier caso, el hermano Carlos encuentra la cima de la unidad -lo buscado en toda místicaen Cristo, palabra encarnada. Por eso, estudiando esas palabras veía en ellas "la entraña misma del misterio de Cristo, de quien no en vano se dice que es la palabra: una palabra que se ha hecho visible, audible, palpable y alimento como carne e historia", (p. 323).

Las palabras nos abren, reconcilian y unen al mundo. E1 cuerpo y el espíritu, los sentidos y el logos, encuentran su más perfecta unidad en un Dios que se encarna. Es ahí donde culmina y se consuma el juego de proximidad y distancia. Sin duda tocar al enfermo y al pobre es más que mirarles o escucharles. Pero, 
atendiendo a la secuencia que se despliega en el texto, es mejor aun elevar el tacto diciéndoles palabras de vida eterna. Un reto a la evangelización.

\section{MEMORIA Y OLVIDO. EL TIEMPO RECOBRADO Y EL TIEMPO REDIMIDO. LA ESCRITURA Y EL PERDÓN}

El amor a la escritura que al parecer tenía el protagonista surge en varios momentos de su historia. Antes de su conversión, cuando era geógrafo clandestino recibió los honores que merecía por su investigación; también, ya casi al final, celebra la escritura en su nueva transformación en lexicógrafo. Por último, cuando decide escribir sus memorias. ¿Qué sentido tiene, en la vida y obra de Foucauld, culminar con un elogio de la escritura que es, claro está, de la memoria que implica?

Seducido y fascinado por la lengua tuareg, el ermitaño decide continuar la labor de Motylinski en el diccionario y la gramática. Se maravilló "ante las fuentes, el método y rigor" de su estudio. Pero, sobre todo, porque aquel trabajo era impulsado por el amor a ese pueblo, sus costumbres y lengua. Su personalidad se identifica con la del lexicógrafo. Así, su ermita se iba llenando de palabras que le evocaban los rostros de las personas que podian pronunciarlas. "De este modo, con estas imágenes en mi cabeza, sentí que mi ermita se llenaba de palabras que eran rostros y que el idioma era al fin lo que Dios siempre quiso que fuera: un lugar de encuentro. ¡Cuántas palabras habia en mi ermita! Vagaban por el aire, y yo, como un cazador, las atrapaba como si fueran mariposas!", (p. 320). Como indicamos, no le motiva la fama, sino la firme convicción de que en cada palabra se escondía el misterio de Cristo, el logos mismo que era al principio y eternamente encarnado.

¿Cómo entonces se puede sentir desdoblado? Revestido de un nuevo disfraz y una nueva identidad, la de lexicógrafo, se ve como una especie de "impostor". "Porque con aquel diccionario entre mis manos no era ya un explorador disfrazado de judío o un pobre buscador de Dios con el hábito trapense; no era un falso jardinero o un militar sin vocación, sino que era un lexicógrafo camuflado: una nueva identidad -iuna más!- Para el viejo vizconde de Foucaul”, 
(p. 324). Ante este desdoblamiento, surge la pregunta sobre la identidad de quien hace las anteriores afirmaciones.

Las palabras poéticas de la lengua tuareg tenían que permanecer de modo que "estaba dispuesto a arrancar aquel tesoro cultural de un olvido de siglos. Quería que esas historias y poemas llegaran a cualquier lugar, y que gozaran de la vida propia de los libros", (p. 327). De igual modo, estas palabras nos provocan cierta perplejidad sobre quién sufre la tentación de la idolatría, el vizconde o el autor del libro. Porque no parece compatible endiosar la belleza con el olvido de sí y confianza en su Señor. Más bien nos recuerda la agonía que sufre Marcel, el protagonista de la Recherche, por recobrar el tiempo perdido y por salvarse de la caducidad y de la muerte en la escritura.

Las memorias de su vida se plasman también en escritura. Insistimos. Cualquier lector, llevado por la dinámica de esta historia, puede preguntarse qué sentido tiene escribir unas memorias en un contexto, mejor en un proyecto, de olvido de sí. ¿Memoria u olvido? Como suele ocurrir con los opuestos, se trata también de su unidad. Se recuerda, se hace memoria para olvidarse de sí. Esta es la última paradoja a la que nos lleva el narrador. No se trata de recobrar el tiempo perdido en la memoria, ni siquiera en la escritura. Ni la fama, ni la permanencia en la belleza, ni la profundidad, ni siquiera la sinceridad de sus escritos impulsan al peregrino porque él poseía ya, en esperanza, su final.

Se trata de aclarar lo que en el fondo motiva la escritura de estas memorias, la finalidad de ese análisis y descripción minuciosa de cada episodio de la vida del protagonista, del horizonte finalmente desde donde se narra. El escritor que también fue el vizconde converso, ¿'se impone al asceta, al sacerdote y al místico? ¿Cómo puede uno olvidarse cuando se anhela que las palabras escritas perpetúen sus acciones?

Diversas razones se ofrecen en el texto para justificar las memorias. Para que las lea su amada ya que son expresión de la purificación de su vida; para mostrar al mundo "su pequeñez"; para "servir de acicate" a todos los que tengan su mismo impulso y quieran que su vida sea "una decidida conquista de la libertad"; 
para "advertir del peligro de la dispersión (" He escrito este libro para deciros que la mayor miseria del hombre es la dispersión",( p. 363); para conocer su "dimensión más mística y espiritual". Así, escribe sus memorias "con la esperanza de que durante su lectura alguien pueda escuchar la voz del silencio que yo mismo escuché y para que sea capaz de responder a ella, si puede, mejor de lo que yo respondia", (24). Pero el motivo más radical es dar gloria a Dios, manifestar su presencia en la vida de este místico itinerante.

Por eso el lector malicioso tiene que sorprenderse de nuevo al atender al testimonio del narrador que, con suma autoconciencia, lo indica. Para ello ha de leer los parágrafos $\& 92$, \& 93 conjuntamente con el \&2, (páginas 24-26; 335-342). Ahí se condensan las cuestiones relativas a las motivaciones y finalidad de la escritura en una vida que luchó por olvidarse de sí. Su vida, confiesa, no merece ser narrada por su riqueza de episodios, ni de sus viajes, ni de sus transformaciones. Tampoco por ser "exótica o extravagante", sino por haber sido, desde su conversión, "un eco de la de Dios". Además, solo él puede contarla porque es el único que sabe "el secreto" que vivieron Dios y él mismo en los momentos de ayuno y oración. "Narraré pues la historia del amor más grande que pueda conocer un hombre que no es otro que el amor de Dios", (p. 24).

Esta visión lúcida brota poco antes de morir. E indica la fecha del comienzo de su autobiografia (páginas 26 y 336), el 1 de enero de 1916. Desde esa perspectiva, lo importante es como Dios le iba conduciendo hasta su final. Por ello, El olvido de si expresa el amor y fidelidad que Dios tuvo con el protagonista a pesar de su falta de respuesta adecuada. Pero al final todo se condensa en una palabra: agradecimiento.

Paradójicamente ese olvido será la memoria del más profundo yo: el que se constituye por el amor de un Dios que le otorga su más insondable identidad una vez que había logrado espacio para acogerlo. Por ello, su testamento, su herencia, es el don de su escritura. Frente a la grandeza de este olvido, resulta patética la muerte de Bergotte, el modelo de escritor de la Recherche. La permanencia en la fama es entupida ante el destino de la corrupción, como indica el narrador. 
Es importante insistir quién es el que recuerda, desde qué actitud, y qué sentido tiene el recordar. La memoria es un poder que puede estar lesionado, inhibido o manipulado. El protagonista narra como un ser que se siente reconciliado consigo mismo por el perdón. Un "olvido feliz", un poder liberador. Por ello, interpreta su pasado en clave de redención al descubrir, desde su conversión, su nuevo sentido. En consecuencia, el círculo que se inicia con el deseo de olvidarse y se cierra con el martirio, pasa por la memoria que actualiza el pasado, lo trae a presencia para poder renunciar a él. Por eso la relación entre memoria y olvido se hace más íntima y entrelazada.

El tiempo recobrado, desde la conversión religiosa, libera a la memoria de toda repetición compulsiva reconciliándola con lo vivido. El trabajo de la rememoración queda cambiado por el perdón, lejos de un tiempo detenido, que se niega a pasar. Al ser perdonado, recupera el pasado y queda libre de su peso para entregarlo y olvidarlo.

Pero la memoria adquiere mayor firmeza y permanencia cuando se hace escritura: es un reto ante la fugacidad del tiempo. Modélica es la pasión de Marcel por la escritura y el anhelo de perpetuidad que implica. El temor a que el tiempo le arrebate la vida antes de culminar la obra que está escribiendo, planea como una sombra abrumadora sobre el protagonista de la novela de Proust. La misma obra que el lector tiene en sus manos y está a punto de concluir como le ocurre con El olvido de sí. "Y viviría con ansiedad de no saber si el Árbitro de mi destino, menos indulgente que el sultán Sheriar, por la mañana, cuando interrumpía mi relato, se dignaria aplazar la ejecución de mi sentencia de muerte y permitirme continuarlo la próxima noche", afirma el narrador de El tiempo recobrado. Ante la anticipación de su propia muerte y la de su libro, solo le cabe a Marcel resignación.

Estamos, insistimos, en las antípodas de la actitud ante la muerte que tiene Foucauld. Nada de ese temor encontramos en la vivencia del tiempo cuando presiente su propia muerte. No busca el tiempo perdido para recuperarlo en el recuerdo, ni siquiera en la escritura de sus memorias porque ésta no obedece al deseo de permanencia. Desde su conversión, el tiempo se recupera en la oración. En ella 
queda salvado, redimido. Por ello, quiere rescatar del olvido su experiencia de cristiano para ofrecerla a sus hermanos. Aunque, obedeciendo el consejo de su confesor, del padre Huvelin, quien le indicó el título, el verdadero motivo de sus memorias es manifestar la presencia de Dios en su vida, "ahora sé que escribo para contar al mundo que he sido amado con un Amor incomprensible y sobre humano. Escribo porque me sé amado. Ninguna otra razón justificaría mi escritura...", (p.338). Y, añade, que esa es la única razón que "debería impulsar eso que llamamos literatura" Ante esos textos citados, los lectores de Proust que hemos gozado y amado sus palabras solo podemos permanecer en silencio.

El pasado es en la misericordia del Señor que lo salva y redime eternamente de la disolución (y no queda al azar del olvido y del carácter también efímero de la escritura). Estamos ante una vocación esculpida por un único cuidado: el ayuno, la oración, la limosna que culmina en un silencioso y misterioso martirio. Es el mejor modo de imitar a su modelo, Cristo. Por eso nuestro protagonista fija su autobiografia en unas Memorias que expresan el avance del olvido de sí. Su escritura le lleva a concluir que "escribir y amar" era lo mismo para él. Además, le sostiene la certeza de que "cuando me digo de algún modo -del único posible- digo al propio Dios", (p. 338). Es la única razón "por la que el don de escribir es tan maravilloso". El camino que lleva de la confusión a la iluminación, del tener al ser, de la búsqueda del éxito a la aceptación del fracaso culmina con un último gesto: unas memorias escritas.

Y el martirio. Con este supremo acto de amor y ejemplaridad, el hermano universal nos lega, además de sus Memorias, su martirio, el mayor olvido de sí. Él mismo nos indica con un recuerdo de $\mathrm{S}$. Ignacio lo que le agradece su escritura en la faena de su propio discernimiento espiritual o tarea de autoconciencia. "¡Bendito Ignacio que experimentó, puso por escrito y transmitió el precioso tesoro de su propia exploración", (p. 116). Gracias a la lectura de Ejercicios espirituales, regalo de Huvelin, se unía a S. Ignacio por un mismo impulso "su virulencia y su temperatura". En consecuencia, son fines apostólicos, los que le impulsaron motivando profundamente la redacción de sus memorias, aunque también latieran en los márgenes, de forma subsidiaria, otros que hemos indicado. Pero la escritura nunca es, en este texto, el último 
reducto del narcisismo, sino el último recurso para olvidarse de sí. Porque poco puede importarle a alguien que pide al martirio la permanencia de su vida mundana si es, desde su conversión, un continuado esfuerzo por "abajarse". Y menos todavia a quien presintiendo su muerte la ve desde el amor de Dios.

\section{¿QUÉ NOS QUEDA? AL CERRAR EL LIBRO...}

Volcados e inmersos en el protagonista, en la riqueza de su vida, en el mundo del texto, este espléndido libro nos hace olvidar que se trata de algo configurado por su autor, de una construcción literaria. Como es habitual en sus novelas, el decir sirve tanto al mostrar que las palabras nos llevan sin mediación, con total transparencia, a la vida narrada. Además, la unidad entre ficción y realidad fluye de maravilla al conjugar la vida del vizconde con la del narrador.

Todos los temas que interesan al autor se despliegan y concentran en esta excelente obra. La quietud y la luz juegan con el movimiento y la penumbra hasta introducirnos en la más profunda oscuridad. Pues, como el viajero en la noche reconoce, su vida en el fondo "es fundamentalmente angustia y egocentrismo". Pero también iluminación y generosidad. El lector familiarizado con la obra de Pablo d'Ors queda encantado con el reconocimiento sucesivo de todos los motivos de su narrativa: la búsqueda de la identidad, la acción y la contemplación; la exaltación de los sentidos y el poder de la palabra, el éxito y el fracaso, la voluntad y la gracia. Y, sobre todo, como hilo conductor, la llamada de una vocación que se va configurando a través de una vida turbulenta y proteica que descubre su identidad mas profunda en la desposesión mas radical, en el vacío interior. Pero todos estos elementos, se presentan integrados e iluminados por un nuevo resplandor: el que ofrece el sentido religioso de la existencia.

No podía faltar tampoco para descanso del lector, en esta obra radical y profunda, los toques de humor en las extravagancias. Pero de un humor purificador, una de las mejores formas del amor, que provoca la sonrisa más benévola. También en este aspecto estamos lejos del amargo, cáustico y defensivo humor de las Ideas. Así, vemos al recadero de las clarisas, preso de la 
alucinación, deambulando por las calles de Nazaret identificando a cada persona que ve con un personaje evangélico. La samaritana, Natanael, Marta y María paseando del brazo, un "desarrapado" que era el Bautista, una mujer corriendo, la adúltera, huyendo de las pedradas... Y así hasta que se miró en una fuente y se quedo sorprendido viendo al mismo Jesús que le sonreía. La identificación con Cristo le lleva hasta tales extremos. Pero nos alegramos con su locura que ha recuperado la inocencia de la infancia. Un pasaje redondo, con ritmo vibrante, que rebosa ternura y al que remitimos para regocijo del lector.

Vuelve a reaparece el humor cuando el protagonista comprende el valor sagrado de toda vida humana sintiendo un irrefrenable impulso de postrarse ante ella. Postraciones sin término se suceden ante todo el que se cruza en su camino demostrando literalmente la actitud de humildad ante la presencia de Dios en el hombre. De mismo modo, maravillado de los poderes de su tacto, no para de tocar a quienes se le acercan... ¡hasta verse lleno de piojos de tanta proximidad con los harapientos! Y, como última muestra, le vemos perseguido y atosigado por la enamorada admiradora y propagandista de su obra, Susana Perret, que lo "asfixiaba" con sus atenciones y tiene que mantener a distancia para que no le lleve a perder la paciencia. En fin, en estos episodios nos asombramos de su locura y extravagancia. Pero, sobre todo, disfrutamos con la brisa del buen humor.

A la perfección estructural se une el modo de desarrollar la obra en una esmerada unidad de despliegue. Admirable, decíamos, es la secuencia que se establece en el desarrollo del texto. Está tan sumamente cuidado que cada capítulo encuentra su lugar exacto donde está situado así como cada parágrafo. Por ejemplo, la purificación precede a la compasión y ésta a la iluminación. Dentro ya de cada capítulo, los parágrafos se entrelazan con una fluencia sorprendente anticipando algunas ideas que serán retomadas y desarrolladas después. Así, la intercesión alcanza su plenitud en "Todos los nombres" pues con ellos el peregrino va descubriendo su identidad más profunda al mismo tiempo que diversos aspectos de Dios. El momento posterior estaba implicado germinalmente ya en los anteriores de tal modo, por ejemplo, que la iluminación latía ya en el modo de mirar, escuchar y tocar. Por eso el peregrino quedaba 
retenido, en esa plenitud de los sentidos, por cada realidad mirada, escuchada, acariciada, amada Y embelesado en ellas. De este modo se va imponiendo la dimensión temporal del presente: cada vez hay menos tendencia, más atención, más permanencia. La lucidez brota iluminando todos los objetos y a él mismo no como fruto del trabajo esforzado, sino como un don. Y lo más prodigioso era el origen de la luz: surgía del sagrario iluminando toda la realidad. "Bajo esa luz todo me parecía sencillo e indiscutible, amable y perfecto”, (p. 359).

Todo, en este apasionante texto, está lleno de contrastes que se encuentran en una síntesis que no excluye nada. Pues las oposiciones no se mantienen aristadas sino en una gozosa unidad. Estamos, de nuevo, en oposición a las contradicciones y exclusiones de Las Ideas puras. O esto o lo otro pero nunca la armonía, se muestra allí. Por eso el mundo de Platón-Vittgenstein, su protagonista, esta escindido, partido, sin que el angustiado profesor consiga establecer la unidad ni siquiera al final de su vida. De la eterna y tediosa repetición del conflicto se ha llegado, para alegría del lector, a la más bella armonía en la oposición de los contrarios. Y es que el movimiento de la trascendencia eleva las diferencias a su más profunda unidad. Del mundo fracturado se nos conduce a un mundo integrado, aun después de una gran lucha y tesón, pero con la Gracia.

Dialéctica con síntesis, una maravilla: el tacto y la palabra elevados en el misterio de la encarnación -el Logos se hace carne-; la dimensión social y la religiosa, preludiando el cuerpo místico de Cristo. El poder de la intercesión culmina en "todos los nombres", trece, retomados en una acción de gracia; la unidad de esfuerzovoluntad y gracia, "No hay camino a Dios sin esfuerzo humano, aunque el esfuerzo, ciertamente, no sea el camino para llegar a Dios. Dios nos pide esfuerzo para que veamos su inutilidad y nos abramos a su gracia", (p. 305). Los dos aspectos de la eucaristia, la adoración y la comunión se aúnan, por más que al autor prefiera la Adoración por las razones que ofrece. Y no abunde más, como el lector desearía, en la comunión.

El final de esta prodigiosa aventura nos eleva más allá del éxito y del fracaso. Ambos se complementan en una indiferencia que, por santa, los mantiene trascendidos (\&105). Pues nos llena de 
esperanza, en fin, que cada acontecimiento importante de esta vida pueda ser interpretado en clave de fracaso o de éxito: una cura para los dogmatismos. Aunque lo más importante es mantener las diferencias en unidad, pues a esas alturas de su vida prevalece la indiferencia. Su corazón está desasido de todo y anclado en Cristo. Nada suyo lo retiene. Por eso nos quedamos absortos con la confesión de este "místico itinerante": "Nada de lo mío -mis cosas, mi historia, mi cuerpo, mis ideas..."- me interesa ya porque todo eso ha ido perdiendo sus contornos hasta el punto de no haber nada en absoluto salvo El: estoy desposeído, finalmente soy el hombre que estaba llamado a ser", (p. 376). Dicho humanamente, es la vocación cumplida. Y, místicamente, la "Suma de la perfección", donde "Todo es ya gracia".

En conclusión, la unidad de soledad y compañia cuando presiente su muerte, pues al aumentar la soledad se siente cada vez mas "intimamente acompañado". Pero lo mas importante es que todos estos opuestos que hemos indicados se encuentran en momentos de una sublime unidad.

¿Qué nos queda al cerrar el libro? Nos queda la claridad y el esplendor de la palabra escrita, el goce estético y un mundo que nos interpela. Como al término del mejor de los viajes, la impresión de haber llegado al hogar, al lugar que nos estaba esperando, donde nos gustaría permanecer. Pues toda vocación cumplida es, en cierto modo, un reflejo del paraíso. Estamos ante una obra maestra que mantiene al lector en estado de fascinación alternando con momentos de inquieta lucidez. Este texto, en muchos aspectos tan prustiano, no por el estilo, ni por el sentido último de su mundo, sino por sus temas centrales, (la búsqueda de salvación, la vocación de la escritura, el tiempo perdido y recobrado, la importancia de los espacios de silencio...), es una apasionante invitación a leer en sí mismo, a meditar y contemplar. Su mundo, abierto a diversos lectores, entusiasmará a todos los que gocen con la palabra buena, verdadera, bella. Los lectores no creyentes pueden sentirse impulsados a explorar espacios espirituales que les lleven a la reflexión, a profundizar y enriquecer su experiencia. Y, a los creyentes, el acto de leer les invitará a orar. En cualquier caso, la lectura de esta obra edificante es un estímulo para refigurar profundamente la propia vida del lector. 